6 British Association for Counselling, Counselling in Medical Settings Division. Counselling in general practice. Report of a working party. London: British Association for Counselling, 1985.

Garfield SL, Kurtz R A survey of clinical psychologists; characteristics, activities and orientations. Clinical Psychologist 1974;28:7-10.

8 Freeman GK, Button EJ. The clinical psychologist in general practice: a six year study of consulting patterns for psychosocial problems. F R Coll Gen Pract 1984;34:377-80.

9 Pendleton D, Schofield T, Tate P, Havelock PB. Educational settings. In: The consultation: an approach to learming and teaching. Oxford: Oxford University Press, 1984:73-82.

0 Anonymous. Is counselling the key? [Editorial]. I R Coll Gen Pract 1980;30:643-4.

11 Milne RM. Counselling and the doctor. I $R$ Coll Gen Pract 1983;33:604.

12 McLeod J. The work of counsellors in general practice. London: Royal College of General Practitioners, 1988. (Occasional paper 37. )

13 Martin E. Counselling in general practice. $\mathcal{F} R$ Soc Med 1985;78:186-8.
14 Gray DP. Counsellors in general practice. IR Coll Gen Pract 1988;38:50-1.

15 Robson MH, France R, Bland $M$. Clinical psychologist in primary care: controlled clinical and economic evaluation. BrMed f 1984;288: 1805-8.

16 Martin E, Martin P. Changes in psychological diagnosis and prescription in a practice employing a counsellor. Fam Pract 1985;2:241-3.

17 Earll L, Kinley J. Clinical psychology in general practice: a controlled trial evaluation. $f R$ Coll Gen Pract 1982;32:32-7.

18 Irvine J. Counselling in general practice. $\mathcal{F} R$ Soc Med 1985;78:785

9 Weiss SM, ed. Proceedings of the Heart and Lung Institute working conference on health behaviour. New York: Department of Health, Education, and Welfare, 1976. (Publication No (NIH) 76-868.)

20 Martin E. Counselling in general practice. $\mathcal{f} R$ Soc Med 1985;78:785-6.

21 Corney RN. Marriage guidance counselling in general practice. $\mathcal{f} R$ Coll Gen Pract 1986;36:424-5. 22 Hampton JR. The end of clinical freedom. Br Med f 1983;287:1237-8.

\title{
Smoking and leukaemia
}

\section{Leukaemia commoner among smokers but why?}

Cigarette smoking has been so extensively researched and linked to so many different diseases that there is an initial sense of disbelief at the suggestion that it may cause yet another disease-namely, leukaemia. That the possible link has not received much attention is not surprising because only a few prospective studies of smoking are large enough to detect even a $100 \%$ increase in the risk of leukaemia in smokers, and many case-control studies of leukaemia have not obtained information on smoking.

In 1985 Austin and Cole reviewed the epidemiological evidence and suggested that there was an association between smoking and leukaemia, especially acute myelocytic leukaemia. ${ }^{1}$ They said that confirmation was needed, and since then confirmation has been found. A case-control study showed that cigarette smoking was associated with a significantly increased risk of acute myelocytic leukaemia (relative risk $1 \cdot 78,95 \%$ confidence interval $1 \cdot 01$ to $3 \cdot 15$ ). Now Kinlen and Rogot report the largest prospective study smoking and leukaemia ( $p$ 657). It provides the results of 16 years of follow up from the United States veterans study (eight years longer than was available to Austin and Cole in their review) and includes details of the type of leukaemia. The study shows a significant increase in the risk of leukaemia associated with smoking (relative risk 1.53, $\mathrm{p}<0.005)$ together with a dose-response relation between cigarettes smoked and risk; the relative risks were $1.34,1.56$, and 1.59 for people smoking less than 10,10 to 20 , and more than 20 cigarettes daily. Again the strongest effect was found for leukaemia of the myeloid and monocytic types.

The association between smoking and leukaemia is undoubtedly real, but is it one of cause and effect? Could it be an artefact of diagnosis? Metastatic lung cancer, for example, producing leucoerythroblastic cells in the peripheral blood, might be misdiagnosed as leukaemia. This type of error is unlikely to have occurred often enough however, to account for the observed relative risk. Associations with a relative risk of about 1.5 may be due to an indirect association: smoking may thus be associated with some other (confounding) factor that is itself associated with leukaemia. But identifying such a factor is difficult. Consumption of alcohol, for example, is greater in smokers than in non-smokers but is not known to cause leukaemia. Social class would if anything tend to mask the association between smoking and leukaemia as leukaemia is more common in social class I (professional occupations) but smoking is more common among people in partly skilled and unskilled occupations. If the association is one of cause and effect no mechanism has been identified. Benzene and Benzene and ionising radiation cause leukaemia in man, and tobacco smoking is a source of both-but in quantities so small that they are unlikely to make any material contribution to the excess risk of leukaemia in smokers.

Whatever the mechanism, the balance of evidence suggests that smoking may cause leukaemia. This cancer can now be added to the list of tobacco related causes of death summarised by the World Health Organisation, ${ }^{3}$ including it along with diseases such as bladder cancer in the category "diseases for which the excess mortality in smokers may be partly or wholly attributable to smoking".

NICHOLAS WALD

Professor of Environmental and Preventive Medicine,

and Honorary Consultant,

Medical College of St Bartholomew's Hospital,

London EC1M 6BQ

1 Austin H, Cole P. Cigarette smoking and leukaemia. $\mathcal{F}$ Chronic Dis 1986;39:417-21.

2 Severson R. Cigarette smoking and leukaemia. Cancer 1987;60:141-4.

3 Williams R, Horm J. Association of cancer sites with tobacco and alcohol consumption and socioeconomic status of patients: interview study from the third national cancer survey. $\{N C I$ 1977;58:525-47.

4 World Health Organisation. IARC monograph on the evaluation of the carcinogenic risk of chemicals to humans. Tobacco smoking. Geneva: World Health Organisation, 1985. 